\title{
Right of Knowing and Using Mother Tongue: A Mixed Method Study
}

\author{
Burhan Ozfidan ${ }^{1}$ \\ ${ }^{1}$ Texas A\&M University, United States \\ Corresponding: Burhan Ozfidan, Texas A\&M University, United States. E-mail: b.ozfidan@tamu.edu
}

Received: September 22, $2017 \quad$ Accepted: October 28, $2017 \quad$ Online Published: October 31, 2017
$\begin{aligned} & \text { doi: 10.5539/elt.v10n12p15 } \\ & \text { URL: http://doi.org/10.5539/elt.v10n12p15 }\end{aligned}$

\begin{abstract}
Language is a crucial factor for the academic achievement of minority people. Speaking the mother tongue in school increases self-confidence and thinking skills, and conveys freedom of speech. Mother tongue is an inseparable element of his or her culture and that everyone has the right to learn his or her mother tongue. The main objective of this current study is to illustrate the need for a language curriculum and to investigate what parameters will influence the development of a mother tongue. This study used an explanatory sequential mixed method, conducted in two phases: a quantitative phase followed by a qualitative phase. For quantitative data collection, 140 participants responded the survey instrument. For qualitative data collection, 12 participants were interviewed. The results indicated that everyone has the right to be taught in their mother tongue. Mother tongue education is necessary for a student to have an equal access to education and gain benefits from education as do others. Mother tongue education has a crucial role in ensuring school attendance, raising the quality of education, and integrating children into society. Therefore, the findings reflected that a bilingual education program is necessary to be educated in mother tongue.
\end{abstract}

Keywords: mother tongue, language, mixed method, education

\section{Introduction}

Children who have a good knowledge of their mother tongue have been shown to have better literacy skills in a language that is spoken in school (Baker, 2000; Skutnabb-Kangas, 2000). Developing a mother tongue improves not only the mother tongue in the school, but also the aptitudes in the language that the majorities speak in the school (Ozfidan, Machtmes, \& Demir, 2014). According to Cummins (2000), this conclusion indicates that knowing two languages helps children achieve better results in schooling and brings the benefits of linguistic advantages. If children in a school are taught efficiently in their mother tongue, they do better in most school subjects. However, the conceptual and personal foundation of students is damaged if they are discouraged in using their mother tongue (Baker, 2011; Ozfidan, 2014).

The main objective of this current study is to illustrate the need for a language curriculum and to investigate what parameters will influence the development of a mother tongue. Mother tongue education does not present an obstacle for students to learn the official language alongside their mother tongue (Ozfidan, Burlbaw, \& Kuo, 2016). Children's skills and knowledge are conveyed across languages from their mother tongue that is being used at home to the school's language. According to Cummins (2000), cross-languages transfers can occur in two ways. First, the literacy abilities, language, and subjects that are being taught in the majority language can be transferred to the language that is spoken at home if the children's mother tongue is developed and promoted in school. Second, if the educational environment allows children to access to both languages, these two languages can help develop each other. Usage of the mother tongue based in a bilingual education program, according to Malone (2007), allows children who use a language that is spoken in a non-dominant society to build a strong educational based in the language they know best - their mother tongue - and a strong bridge to the official language - the school second language (L2) — and learning other languages as well (e.g., third language, fourth language, and so on). The result is that they may be inspired to use all their languages that they have learned for life-long learning (p. 12).

According to the 2011 DISA report, bilingual education programs have three general approaches: 1) linguistic, 2 academic, and 3) socio-cultural. These approaches are discussed below.

\subsection{Linguistic Approach}

Students entering school should begin building confidence in their capability to connect and socialize with 
people in their mother tongue. Students should build a basis of experience and knowledge during interactions and observations with adults and peers in their society from an early age. The knowledge, experience, and language that students bring to school form a vital foundation for learning in the classroom. Students can also learn their second or third language to use in their communication and to gain self-efficacy.

\subsection{Academic Approach}

Students should reach the required level of academic proficiency in class. In academic content courses, students should be taught in their mother tongue while they study their second language (dominant language). This will enable the students to learn such subjects as math, science, and history while developing their language capabilities.

\subsection{Socio-Cultural Approach}

The socio-cultural perspectives of bilingual education should be used to create language and educational policies for the media. In addition, language should be transferred from teachers because they play an essential role in children's school experiences. Teachers should encourage students to conserve and maintain their own social heritage, culture, and language, thus contributing to their rights and developing their country.

One way to protect the languages of minority groups whose mother tongue is a language other than the state's official language is to learn mother tongue within the formal education system. Currently, many minority groups whose mother tongue is gradually losing power or are gradually facing extinction have been demanding that their mother tongue be taught to their children within the formal curriculum in Turkey.

\section{Method}

This study used an explanatory sequential mixed method, conducted in two phases: a quantitative phase followed by a qualitative phase. The explanatory sequential mixed method began with the gathering and analyzing quantitative data. In the second phase, qualitative data were collected and analyzed as a follow-up to the quantitative results.

\subsection{Data Settings and Analysis}

Descriptive analysis was used describe the basic features of the data and to provide simple summaries about the sample and the measures for the quantitative part of the study. Data that was interval in nature was reported in means and standard deviations. Using Kaiser's rule, factors were extracted and a plot of the eigenvalues was provided. SPSS statistical program version 13.0 was used to conduct data analysis. All the raw data were downloaded into an Excel spreadsheet, and all data fields on each instrument were verified and corrected if necessary to ensure to accurate data was analyzed in this study.

The qualitative part of the study was collected using a semi-structured approach. A semi-structured interview is a qualitative method of inquiry. A semi-structured interview is open in contrast to a structured interview, and a semi-structured interview can accept novel thoughts brought up during the interview because of what the interviewee says (Harrell \& Bradley, 2009).

Different types of questions may be used for semi-structured interviews within the mixed method. For the purposes of the study, the study used descriptive and structural questions. Descriptive questions were used so that participants could discuss the topics more easily. Structural questions helped in the recognition and categorization of relationships between questions and topic. Structural questions are used to build and verify the structure of items and relationships among these items (Harrell \& Bradley, 2009). While asking these questions, providing and explaining context including examples such as bilingual education programs in Spain and Canada was essential.

Thematic analysis was used to analyze interview data. As a first step in analyzing interview data, all interviews were transcribed and carefully read, and notes were taken on hard copy. Second, the initial interpretive and descriptive categories were developed based on evidence presented in the transcripts and the literature review and conceptual framework guided the research while doing that. According to Ely and Associates (1991), a theme as "a statement of meaning that runs through all or most of the pertinent data, or one in the minority that carries heavy emotional or factual impact" (p. 150).

\subsection{Participants}

For quantitative data collection, 140 participants responded the survey instrument. Participants included 96 males and 44 females. For qualitative data collection, 12 participants were interviewed; 6 of whom were Turkish and the other 6 had ethnic backgrounds other than Turkish. In accordance with the IRB guidelines of Texas A\&M University (reference \#043138), the participations were voluntary, and they could drop out at any phase of 
the study if they did not want to continue.

\subsection{Reliability and Validity}

Triangulation was used in both the quantitative and qualitative parts of the study. By approaching data from different advantage points using distinctive procedures and methods, triangulation allows the determination of various aspects of the phenomena more accurately (Denzin, 1978). Reliability was achieved by using triangulation. According to Morse (1994), applying reliability and validity in both quantitative and qualitative research are distinct processes.

Cronbach's alpha was used to analyze the questionnaire data for reliability. Because factor analysis was used, Cronbach's alpha scores were created while running the data on SPSS. Cronbach's alpha internal consistency measure was found to be high across all 7 items $(\alpha=.98)$. For Cronbach's alpha, a minimum value of .70 is considered acceptable (Nunnally, 1978). Hence, the survey instrument was reliable.

Likewise, academicians who are experts in the field of bilingual education in Turkey and the United States reviewed the questionnaires for content/face validity. The results for validity in the survey indicated a statistically significant correlation. The correlation $(\mathrm{rs}=.520, \mathrm{p}=.000)$ can be considered to be a moderate/medium correlation (.40 -.60). (See Laerd Statistics, n.d.) Therefore, this questionnaire was found to have content validity.

\section{Findings}

The quantitative data was collected from the survey instrument, and the results were reported in the quantitative data findings. The data that were collected from the interview instrument, and the results were reported in the qualitative data findings.

\subsection{Results of Quantitative Data Analysis}

Table 1 provides an overall summary of the descriptive findings about the right of knowing and using a mother tongue. This table highlights that the mother tongue should not be forbidden in public (Item 1). The findings also show that respondents believe that a mother language is an inseparable element of their culture, and everyone should have the right to learn his or her mother tongue (Items 2, 3, and 4). This table also indicates that speaking the mother tongue in school increases self-confidence and thinking skills, and gives speech freedom (Items 5, 6, and 7).

Table 1. Items and percentage of participants about right of knowing and using mother tongue

\begin{tabular}{|c|c|c|c|c|c|c|}
\hline \# & Statement & $\begin{array}{l}\text { Strongly } \\
\text { Disagree }\end{array}$ & Disagree & Neutral & Agree & $\begin{array}{l}\text { Strongly } \\
\text { Agree }\end{array}$ \\
\hline 1 & $\begin{array}{l}\text { No languages should be forbidden } \\
\text { to be taught or learned. }\end{array}$ & $\begin{array}{l}6.67 \% \\
(9)\end{array}$ & $\begin{array}{l}5.19 \% \\
(7)\end{array}$ & $\begin{array}{l}3.70 \% \\
(5)\end{array}$ & $\begin{array}{l}48.15 \% \\
(65)\end{array}$ & $\begin{array}{l}36.30 \% \\
(49)\end{array}$ \\
\hline 2 & $\begin{array}{l}\text { One's mother language is an } \\
\text { inseparable element of one's } \\
\text { culture. }\end{array}$ & $\begin{array}{l}2.94 \% \\
(4)\end{array}$ & $\begin{array}{l}6.62 \% \\
(9)\end{array}$ & $\begin{array}{l}4.41 \% \\
(6)\end{array}$ & $\begin{array}{l}45.59 \% \\
(62)\end{array}$ & $\begin{array}{l}40.44 \% \\
(55)\end{array}$ \\
\hline 3 & $\begin{array}{l}\text { Everyone has the right to learn his } \\
\text { or her mother language at school. }\end{array}$ & $\begin{array}{l}3.65 \% \\
(5)\end{array}$ & $\begin{array}{l}9.49 \% \\
(13)\end{array}$ & $\begin{array}{l}4.38 \% \\
(6)\end{array}$ & $\begin{array}{l}32.85 \% \\
(45)\end{array}$ & $\begin{array}{l}49.64 \% \\
(68)\end{array}$ \\
\hline 4 & $\begin{array}{l}\text { Children starting their education } \\
\text { with a language that they do not } \\
\text { know are at a disadvantage when } \\
\text { compared to other students. }\end{array}$ & $\begin{array}{l}3.65 \% \\
(5)\end{array}$ & $\begin{array}{l}6.57 \% \\
(9)\end{array}$ & $\begin{array}{l}5.11 \% \\
(7)\end{array}$ & $\begin{array}{l}34.31 \% \\
(47)\end{array}$ & $\begin{array}{l}50.36 \% \\
(69)\end{array}$ \\
\hline 5 & $\begin{array}{l}\text { Speaking the mother tongue in } \\
\text { school increases self-confidence. }\end{array}$ & $\begin{array}{l}6.62 \% \\
(9)\end{array}$ & $\begin{array}{l}5.88 \% \\
(8)\end{array}$ & $\begin{array}{l}5.88 \% \\
(8)\end{array}$ & $\begin{array}{l}38.97 \% \\
(53)\end{array}$ & $\begin{array}{l}42.65 \% \\
(58)\end{array}$ \\
\hline 6 & $\begin{array}{l}\text { Speaking the mother tongue } \\
\text { develops thinking skills. }\end{array}$ & $\begin{array}{l}3.68 \% \\
(5)\end{array}$ & $\begin{array}{l}5.15 \% \\
(7)\end{array}$ & $\begin{array}{l}8.09 \% \\
(11)\end{array}$ & $\begin{array}{l}33.09 \% \\
(45)\end{array}$ & $\begin{array}{l}50.00 \% \\
(68)\end{array}$ \\
\hline 7 & $\begin{array}{l}\text { Speaking the mother tongue gives } \\
\text { speech freedom. }\end{array}$ & $\begin{array}{l}3.70 \% \\
(5)\end{array}$ & $\begin{array}{l}5.93 \% \\
(8)\end{array}$ & $\begin{array}{l}6.67 \% \\
(9)\end{array}$ & $\begin{array}{l}33.33 \% \\
(45)\end{array}$ & $\begin{array}{l}50.37 \% \\
(68)\end{array}$ \\
\hline
\end{tabular}

Note: Items 1 and 7 had 135 respondents, Items 3, 5, and 6 had 136 respondents, and Items 3 and 4 had 137 respondents. " 1 = Strongly Disagree, 2 = Disagree, 3 = Neutral, 4 = Agree, and $5=$ Strongly Agree." 
Table 2 below indicates the mean scores and standard deviation values of each item in Table 1 . The highest mean score in this Table was 4.21, which emphasizes children who are ethnically different than Turkish are suffering from language issues at schools. All the mean scores were relatively high ranging from 4.02 to 4.15 , which indicates that respondents believed that speaking the mother tongue develops thinking skills and gives speech freedom. Among the scores the lowest mean score was 4.02 for "no languages should be forbidden to be taught or learned." Table 2 shows that the $5^{\text {th }}$ item had the highest standard deviation value with 1.15 for "speaking the mother tongue in school increases self-confidence," which indicates that a high level of differentiation in this item. The $2^{\text {nd }}$ item, which was "one's mother language is an inseparable element of one's culture," was the lowest standard deviation value with a value of .98, showing a low level of differentiation. According to Bland and Altman (1996), "a high standard deviation indicates a heterogeneous group" (p. 48).

Table 2. Perception scale on the right of knowing and using mother tongue (Mean scores and standard deviation values)

\begin{tabular}{llll}
\hline$\#$ & Items & Mean & SD \\
\hline 1 & No languages should be forbidden to be taught or learned. & 4.02 & 1.10 \\
2 & One's mother language is an inseparable element of one's culture. & 4.14 & 0.98 \\
3 & Everyone has the right to learn his or her mother language at school. & 4.15 & 1.11 \\
4 & Children starting their education with a language that they do not know are at a disadvantage & 4.21 & 1.05 \\
& when compared to other students. & & \\
5 & Speaking the mother tongue in school increases self-confidence. & 4.05 & 1.15 \\
6 & Speaking the mother tongue develops thinking skills. & 4.21 & 1.04 \\
7 & Speaking the mother tongue gives speech freedom. & 4.21 & 1.05 \\
\hline
\end{tabular}

Note: Items 1 and 7 had 135 respondents, Items 2, 5, and 7 had 135 respondents, and Items 3 and 4 had 137 respondents.

\subsection{Results of Qualitative Data Analysis}

Emergent themes in the interview were coded under two subheadings: Language Barrier, and Rights of Mother Tongue and Elective Courses.

\subsubsection{Language Issues}

Many scholars believe that language is a critical factor with respect to the academic achievement of minority group students (Baker, 2011; Cummins, 2000; Krashen, 1996; Bialystok, 1991). They also believe that the linguistic rights of minority students should be protected to encourage them to communicate in both public and private spheres. They should also be allowed to receive education in their mother tongue and speak their language legally (McQuillan \& Tse, 1996).

In this study, most of the interviewees, whether Turkish or non-Turkish, highlighted the opportunity to use their own language by minority groups could be of crucial importance because using their own language protects their culture and identity and participation in public life. One of the interviewees, who was ethnically Turkish and worked in the eastern part of Turkey, highlighted important points regarding the language issues in eastern and southeastern part of Turkey. He stated that:

Language is a big issue in the eastern part of Turkey where most of the people speak their mother tongue in public. For instance, I work in an institution in Sakarya now and everyone knows Turkish and all classes are taught in Turkish here. However, when I was in Diyarbakir as a primary school teacher, I had a difficult time since almost everyone was speaking Kurdish. Some of my students even didn't know what is the meaning of "come" or "go" in Turkish. They learned nothing in my classes because I was teaching all subjects in Turkish. That was making me feel very bad. Neither their parents nor anyone else around them were speaking Turkish. I think the government should at least have a local bilingual education program in these territories. Otherwise, most of the students will not benefit from opportunities in Turkey. No one can find a job with only Kurdish or Laz or Arabic in Turkey.

He stated that a local bilingual education program in these territories could help minority students to gain a better education for their future. If this language issue is solved, minority students can have equal opportunities in educational environments, and they can feel more comfortable in being involved in society at large. 
Integrating language courses of different ethnic groups in schools, according to an interviewee whose origin was Turkish, could help minority groups be successful and in their education and reinforce their ethnic identity. This interviewee stated that:

I have a friend of mine who was studying the university entrance exam after he completed his high school. His Turkish was not very good, but he was very smart. In his first time, he failed the exam because his Turkish was not good enough to be successful. For the second time, he initially studied Turkish language for about 6 months. After 6-month period, he started studying the actual exam for about 3 months. He got a very high score, and he attended one of the best universities in Turkey. My point is here that if the government will solve the language issue in the country, I strongly believe people from different ethnic groups will be educated very well and integrate with other people.

She also stated that currently many minority students are suffering from the language issue. If the government could resolve this problem, many minority students could be better educated and more involved the community. Thus, the government should find a solution for minority students who fail in state exams and do not continue their education because of the language issue.

All interviewees, whether Turkish or non-Turkish, emphasized that students who complete their schooling in a bilingual education program can more easily learn a second and third language, and this program increases the educational success of students. They also indicated that population in the eastern and southeastern parts of Turkey are not educated well. These regions have fallen way behind in education since people in these territories have language issues when compared to the western part of Turkey. Very few people are going to university in this area. Because most of them fail in their first year of elementary education, they do not continue pursuing their education. Therefore, very few people are educated in these regions. Interviewees also stated that an education system like a bilingual education program should teach them in two languages.

All interviewees were in agreement that a bilingual education program in Turkey might increase school attendance and help reduce ethnic conflicts. In some measure, that is because everyone could express themselves very well in their native language and could feel more comfortable (Rossell \& Baker, 1996). Some on the non-Turkish interviewees stated that a mother tongue shouldn't be destroyed because destroying a language means destroying an identity. If children are going to be educated in their mother tongue, they will be more successful in their academic life as well. Therefore, a bilingual education might help the children of minority groups for educational purposes. Likewise, this type of education could preserve their linguistic backgrounds, cultural heritage, and ethnic and religious identity.

Three of the interviewees whose origins were Turkish were of the opinion that bilingual education strengthens brain development. Bilingual education develops the functions and the shape of certain parts of the brain (Smith, 1994). Children who are bilingual easily deal with conflict situations. An interviewee highlighted that:

Knowing more than one language makes children have strong memories. They can learn the second language easily. They are also cognitively more creative and innovative than other children who know only one language. Being bilingual gives children more global perspectives. If children learn a second language at a young age, this language will be like a native language.

According to all interviewees, many problems are present in the education system, but language remains one of the biggest issues in education for minority students in Turkey. Particularly, one non-Turkish interviewee noted serious problems regarding the Laz, Arabic, and Kurdish languages. He stated that:

There are serious language issues in the education system in Turkey. For instance, there are many Laz people and the majority of them live in the Black Sea Region in Turkey. Currently, even kids who live in this territory cannot speak Laz because they were not taught in their mother tongue. I think we need to open some courses at schools. These courses should require professionally trained teachers. Because of the lack of faculty members, teachers are not trained in the field. Besides, a curriculum is needed. I think the government should work on it.

He also stated that all students of minority groups should be considered in the country's educational framework, and the government should find a way for minority students to continue their education. Doing so is critical for developing a future generation of well-educated Turkish citizens. As one interviewee, whose origin is ethnically different than Turkish indicated, minority languages should not be forbidden in teaching and learning. This interviewee also stated that language is a critical issue for minority groups, particularly among the Syrian refugees, in Turkey.

Such training is important with respect to the educational future of Turkey, particularly in light of the Syrian 
refugees now living in Turkey. Today, more than 3 million Syrian refugees who are resident in Turkey, and they all suffer from not being involved in the society. Because they speak Arabic and not Turkish, they cannot continue their education (Kaya, 2015). As one interviewee said "the government started considering about a bilingual education program for Syrian refugees; however, they do not do anything for our country's minority ethnic groups." He continued "they provide many opportunities for Syrian refugees, but they do not consider their citizens who are ethnically different than majority groups in Turkey." He highlighted that language programs should be provided for both Syrian children and other minority children who are ethnically different from majority children to facilitate social integration and to provide access to education.

Another interviewee whose origin was Turkish observed that, "many Syrian children have been out of school for three or more years and need specialized support to reintegrate into formal education programs, and academic support is needed for those already in school." He also said that "the government started opening bilingual schools for Syrian refugees; however, they do not allow the opening of any bilingual schools for minority people who are ethnically different." However, most interviewees indicated that the government should build a bilingual education program for both Syrian refugees and minority people who suffer from the language.

On the contrary of all interviewees, a Turkish interviewee stated that language is not a main problem in Turkey. According to this interviewee, the main problem is they feel they are losers. She also said:

Language is not a serious issue for minority people. Since they inhabit in Turkey and the official language of the country is Turkish, they all have to learn Turkish language. The government should allow them to learn and use their language in public, but minority languages shouldn't be spoken officially.

The government should teach Turkish language to the minority students. If they learn Turkish language, they can be successful in school.

Restrictions on language rights can impede minority groups indirectly (Gersten, 1985). A bilingual education program could resolve this language issue among different ethnic groups in Turkey. This is essential for minority students who have language issues related to continuing their education and being successful in schooling. According to most interviewees, a bilingual education program could also solve the conflicts among different ethnic groups and thus allow them to understand each other better.

\subsubsection{Rights of Mother Tongue and Elective Courses}

Accessing education is one of the most important rights for human beings (UNESCO, 2003). The right of mother-tongue education is important for a child to have equal access to education and benefit from education with other children (Skutnabb-Kangas, 2000). Therefore, mother tongue education has a crucial role in ensuring school attendance, increasing educational quality and integrating students into society (Fishman, 1972).

An interviewee whose origin is different than Turkish asserted that the Turkish constitution should guaranteed the right to receive mother tongue education for all minority groups in Turkey. Specific regions in which minority people are outnumbered should have a local bilingual education curriculum to be taught in the mother tongue. He also stated that the government should have an appropriate bilingual education model for minority groups according to their locations and the needs of their communities. He also stated that "the essential legislation should come out for minority groups who want to create and run their own educational institutions; and they should be guaranteed that they will not face any political obstacle or arbitrary treatment." Another interviewee whose origin was Turkish stated that universities should open departments on this subject and train teachers who are going to teach in bilingual or multilingual classes. These departments should also focus on preparing textbooks for the courses. Teachers from minority communities should be encouraged to employ and to be an expert in this field.

One interviewee whose origin is Turkish emphasized that students should be educated in their mother tongue and that this would influence their academic achievements positively. This knowledge will also help them to be employed somewhere else more easily. Therefore, a bilingual education program is important for minority groups to protect their mother tongue and identity.

An interviewee whose origin is different than Turkish asserted that all languages of minority groups should be included within the curriculum as elective courses. He stated that "this is their mother tongue and they shouldn't lose their mother tongue. Losing a mother tongue means losing identity." He also emphasized that everyone has the right to be taught in their mother tongue. He also said that these courses should be offered in all public schools "with no claims that courses cannot be run due to lack of teachers" or for any other reason.

Both Turkish and non-Turkish (ethnically different than Turkish) interviewees indicated that everyone has the right to be educated in their mother tongue. An interviewee whose origin is Turkish and who is an expert in the 
field of language learning stated:

While we see elective courses of different minority groups' languages that were introduced in Turkey in 2012 as a positive step in terms of changing the denial and assimilation policies towards mother tongues, we believe that this problem will not be solved with elective courses. We do not believe that the language of any one ethnicity in Turkey is more valuable or more important than that of other ethnicities. We believe that all languages are equal, valuable and important. It is the duty of the state not to simply permit these languages but to protect and maintain them. We demand that all the identities and languages in Turkey receive constitutional protection.

The interviewee also stated that the right of mother tongue is a human right for minority people. When students are not being taught in their mother tongue, they lose their ethnic identity and self-confidence.

Interviewees who have ethnically different backgrounds than Turkish asserted that they were not allowed to speak their mother tongue at school. During the school period, students waited silently every day for five to six hours. Some of them indicated that they established different approaches to communicate with their Turkish friends. For instance, an interviewee who had ethnical background other than Turkish stated:

We spoke our mother tongue, I think it was 1997, at school during the break time. Since we didn't know Turkish, we used a sign language as a second language to communicate with our Turkish friends. We wished school would be over and we could get out of the school and run away and not come back again.

He also stated that "we all as minority students did not want to go to school because we all felt alienated." He said that some of his teachers did not allow them to speak in their mother tongue even during the break time. According to him, "minority students currently might not suffer such a harsh issue, but I know they are not feeling well and they do not want to go to school." To solve this issue and increase school attendance, teachers should care for their minority students and encourage them to become involved in society.

Some of the non-Turkish interviewees asserted that experts should redesign a novel curriculum including new subjects such as the existing and historical or cultural backgrounds of all minority groups in Turkey. Each school should open an elective course comprising history, culture, and religion relevant to minority groups. They stated that the government should redesign the curriculum, which should encourage a culture of coexistence. Class and extracurricular activities, which would help to increase children's awareness of values such as equality and pluralism and would encourage communicating with other ethnic groups in the country, should be encouraged.

Some of the interviewees stated that minory people requested elective courses from the government, but very few of them registered these courses after the government accepted their request. The problem is not lack of teachers or materials; the problem is lack of studnets who would like to learn and improve their mother tongue. A Turkish interviewee stated that:

Since there were not enough student registed the elective courses, the state didn't provide teachers and materials. In my school I talked with our principle, he said if we reached ten students in a class, we would quickly apply the district to provide us teachers and materials.

This interviewee stated that elective courses for minority people were a great opportunity to learn and improve their mother tongue; however, they couldn't use this opportunity. This emphasizes that they are not sincere of bringing a bilingual education program into the curriculum. She also stated that "even if the government will accept to set up a bilingual education program in Turkey, I believe this will not be successful."

All in all, when students receive education in their mother tongue, which was a commonly held idea of interviewees, the interviewees believed that they could express their thoughts, ideas and feelings better in their classes. This, in turn, would give them the self-confidence they need to be successful in their courses. If students see that their mother tongue and culture are valued and vital, they will seek to retain their fluency in their mother tongue (Cummins, 2001).

\section{Discussion and Conclusion}

Findings indicated that someone's mother language was an inseparable element of his or her culture and that everyone has the right to learn his or her mother tongue. In this study, the data reflected that speaking or learning a mother tongue should not be prohibited; on the contrary, learning a mother should be encouraged. Speaking the mother tongue in school was also seen as a way to increase self-confidence and thinking skills and provide speech freedom. According to UNESCO's (1974) reports, the most realistic way to eliminate discrimination between majority and minority students when they begin school is to use their mother tongue in education within a bilingual education model. 
The results of the study reflected that the opportunity to use their own language was vital for minority groups because this usage would protect their culture and identity as well as encourage participation in public life. Language is a crucial factor for the academic achievement of minority people (Krashen, 1996; Ozfidan \& Ugurlu, 2015). When the language issue is solved, minority students can have equal opportunities in educational environments, and they can feel more comfortable in being involved in society. Findings indicated that integrating the language courses of different ethnic groups in schools could help minority groups become more successful in their lives and in their education while reinforcing their ethnic identity. Currently, many minority students suffer from language-related issues in Turkey. The government could solve this problem by inserting a local bilingual education program into the curriculum. A bilingual education program in Turkey might increase school attendance and help reduce ethnic conflicts between different ethnic groups.

According to UNESCO, everyone has the right to be taught in their mother tongue (UNESCO, 2003). Mother tongue education is necessary for a student to have an equal access to education and gain benefits from education as do others. Mother tongue education has a crucial role in ensuring school attendance, raising the quality of education, and integrating children into society (Fishman, 1972). Findings reflected that most minority students did not want to go to school because they felt alienated. Therefore, the government should have an appropriate bilingual education model for minority groups according to their locations and the needs of their communities. Universities should open departments to train teachers who are going to teach in bilingual or multilingual classes. These departments can also focus on preparing textbooks for the courses. Besides, each school could open an elective course that includes the history, culture, and religion relevant to minority groups. And, teachers who are going to be trained at universities can handle these elective courses.

Speaking the mother tongue in school increases self-confidence and thinking skills, and conveys freedom of speech. This also increases academic accomplishment for minority students. Participants in the study believed that everyone has the right to learn his or her mother language at school. Languages should not be forbidden to taught or learned. A common idea of both quantitative and qualitative data was the right of mother tongue as a human right for minority people. Destroying a language means destroying an identity. UNESCO (2003) also affirmed that minority people could learn their mother tongue without being under any pressure because this is a human right. Restrictions on language rights can impede minority groups indirectly (Gersten, 1985). When students receive education in their mother tongue, they can express their thoughts, ideas and feelings better in their classes.

\section{References}

Baker, C. (2000). A parents' and teachers' guide to bilingualism (2nd ed.). Clevedon, England: Multilingual Matters.

Baker, C. (2011). Foundations of bilingual education and bilingualism (5th ed.). New York: Multilingual matters.

Bland, J. M., \& Altman, D. G. (1996). Statistics notes: Measurement error. The BMJ, 313, 744. https://doi.org/10.1136/bmj.313.7049.106

Bialystok, E. (1991). Language processing in bilingual children. Cambridge University Press. https://doi.org/10.1017/CBO9780511620652

Cummins, J. (2000). Language, power and pedagogy: Bilingual children in the crossfire. Clevedon, UK: Multilingual Matters.

Denzin, N. K. (1978). The research act: A theoretical introduction to sociological methods. New York: McGraw-Hill.

Diyarbakir Institute for Political and Social Research, (DISA) (2011). Dil Egitimi Modelleri ve Ulke Ornekleri. (Educational Language Models and Country Examples). Retrieved from http://www.ozgurcerkes.com/FileUpload/ds213192/File/onceanadili2.pdf

Ely, M., Anzul, M., Friedman, T., Garner, D., \& Steinmetz, A. M. (1991). Doing qualitative research: Circles within circles. London: Falmer Press.

Fishman, J. A. (1972). Language and nationalism. Rowley, MA: Newbury House Publishers.

Harrell, M. C., \& Bradley, M. (2009). Data collection methods: Semi-structured interviews and focus groups: Training manual. Santa Monica, CA: RAND.

Gersten, R. (1985). Structured immersion for language-minority students: Results of a longitudinal evaluation. Educational Evaluation and Policy Analysis, 7(3), 187-196. https://doi.org/10.3102/01623737007003187 
Kaya, N. (2015). Teaching in and studying minority languages in Turkey: A brief overview of current issues and minority schools. European Yearbook of Minority Issues Online, 12(1), 315-338. https://doi.org/10.1163/9789004306134_013

Krashen, S. (1996). Under attack: The case against bilingual education. Culver City, CA: Language Education Associates.

Laerd Statistics, (n.d.). Pearson product moment correlation. Retrieved from https://statistics.laerd.com/statistical-guides/pearson-correlation-coefficient-statistical-guide.php

Malone, S. (2007). Mother tongue-based multilingual education: Implications for education policy. Paper presented at the Seminar on Education Policy and the Right to Education: Towards more Equitable Outcomes for South Asia's Children, Kathmandu, Nepal, 1-3 October. Retrieved from https://www.sil.org/resources/archives/42737

McQuillan, J., \& Tse, L. (1996). Does research matter? An analysis of media opinion on bilingual education, 1984-1994. Bilingual Research Journal, 20(1), 1-27. https://doi.org/10.1080/15235882.1996.10668617

Morse, J. M. (1994). Critical issues in qualitative research methods. Thousand Oaks, CA: Sage Publications Inc.

Nunnally, J. C. (1978). Psychometric theory (2nd ed.). New York: McGraw-Hill.

Ozfidan, B., Burlbaw, L., \& Kuo, L. J. (2016). Perceptions of an Anticipated Bilingual Education Program in Turkey. International Education Studies, 9(10), 174. https://doi.org/10.5539/ies.v9n10p174

Ozfidan, B., \& Ugurlu, O. (2015). The Idea of Race and Racial Differences. Electronic International Journal of Education, Arts, and Science, 1(1), 85-98

Ozfidan, B., Machtmes, K., \& Demir, H. (2014). Socio-cultural Factors in Second Language Learning: A Case Study of Adventurous Adult Language Learners. European Journal of Education Research, 3(4), 185-191. https://doi.org/10.12973/eu-jer.3.4.185

Ozfidan, B. (2014). The Basque bilingual education system: a model for a Kurdish bilingual education system in Turkey. Journal of Language Teaching and Research, 5(2), 382-390. https://doi.org/10.4304/jltr.5.2.382-390

Rossell, C., \& Baker, R. (1996). The educational effectiveness of bilingual education. Research in the Teaching of English, 30(1), 7-74.

Skutnabb-Kangas, T. (2000). Linguistic genocide in education-or worldwide diversity and human rights? Mahwah, NJ: Lawrence Erlbaum Associates.

Smith, F. (1994). Understanding reading: A psycholinguistic analysis of reading and learning to read (5th ed.). Hillsdale, NJ: Lawrence Erlbaum.

UNESCO. (1974). Recommendation concerning education for international understanding, co-operation and peace and education relating to human rights and fundamental freedoms. Adapted by the General Conference at its Eighteenth Session, Paris, 17 October-23 November. Retrieved from http://unesdoc.unesco.org/images/0011/001140/114040e.pdf\#page $=144$

UNESCO. (2003). Education in a multilingual world. Paris: Paris: United Nations Educational, Scientific and Cultural Organization. Retrieved from http://unesdoc.unesco.org/images/0012/001297/129728e.pdf

\section{Copyrights}

Copyright for this article is retained by the author(s), with first publication rights granted to the journal.

This is an open-access article distributed under the terms and conditions of the Creative Commons Attribution license (http://creativecommons.org/licenses/by/4.0/). 